\title{
Premixed flame chemistry of a gasoline primary reference fuel surrogate
}

\author{
Hatem Selim $^{1, \#, *}$, Samah Y. Mohamed ${ }^{1}$, Nils Hansen ${ }^{2}$, S. Mani Sarathy ${ }^{1}$
}

\begin{abstract}
Investigating the combustion chemistry of gasoline surrogate fuels promises to improve the detailed reaction mechanisms used for simulating their combustion. In this work, the combustion chemistry of one of the simplest, but most frequently used gasoline surrogates -primary reference fuel 84 (PRF 84, 84\% iso-octane and 16\% n-heptane), has been examined in stoichiometric premixed laminar flame. Time-of-flight mass spectrometry coupled with a vacuum ultraviolet (VUV) synchrotron light source for species photoionization was used. Reactants, major endproducts, stable intermediates, free radicals, and isomeric species were detected and quantified. Numerical simulations are conducted using a detailed chemical kinetic model with the most recently available high temperature sub-mechanisms for iso-octane and heptane, built on the top of an updated pentane isomers model and AramcoMech $2.0\left(\mathrm{C}_{0}-\mathrm{C}_{4}\right)$ base chemistry. A detailed interpretation of the major differences between the mechanistic pathways of both fuel components is given. A comparison between the experimental and numerical results is depicted and rate of production and sensitivity analyses are shown for the species with considerable disagreement between the experimental and numerical finding.
\end{abstract}

Key words: Primary reference fuels, flame chemistry, fuel surrogates, molecular beam mass spectrometry, detailed reaction mechanisms

\section{Introduction}

While the depletion of fossil fuels motivates the need for alternative energy resources, it is equally important to improve the utilization of available resources. Consumption of fossil fuels occurs through the transformation of chemical energy to thermal energy through combustion processes. The energy consumed in transportation, where gasoline and diesel fuels are predominantly used, has increased consistently in the past 50 years [1]. This increasing demand motivates higher fuel efficiency, thus a better understanding of the fuel combustion process is 
indispensable. Extensive studies must be performed in order to advance current knowledge about combustion chemistry and kinetics of these fuels. However, gasoline, diesel and kerosene fuels contain hundreds of compounds, including additives for lubrication, knock resistance [2], fuel icing resistance etc.; making it very challenging to experimentally examine these fuels in fundamental research. Subsequently, research in the combustion community is largely focused on the study of single component fuels [3-11], while greater levels of complexity are often explored by doping a secondary component [12-21].

Recently, combustion of hydrocarbon up to $\mathrm{C}_{8}$ [22-25] have been extensively investigated; however, the interaction among the multiple fuel components within the reaction pool is still highly ambiguous. Consequently, several approaches were used to achieve a greater resemblance to the behavior of the actual fuels in combustion applications. One approach was to use a surrogate fuel mixture [26-29], with tailored physical and thermochemical properties similar to those of the actual fuel. Examples of these mixtures are primary reference fuels (PRF), for gasoline fuels [30], JP-8 surrogates for aviation fuels [31], and biodiesel surrogates for biodiesel fuels [32]. Another approach is to develop multi-component fuels such as FACE (fuels for advanced combustion engines) fuels [33], which can be used for research purposes. FACE fuels do not have as many components as commercial gasoline fuels, but they represent their physical and chemical properties (e.g., octane number, $\mathrm{H} / \mathrm{C}$ ratio, volatility characteristics, density, etc.) with great accuracy, and they are used to facilitate the comparison of results from different research institutes.

In general, most of the research using the above mentioned approaches was aimed at identifying basic properties, e.g., ignition delay time [34], lift-off height [35], fuel droplet evaporation [36], flame speed [37], and heat release profiles [38]. Very recently Selim et al. [39] published one study about the flame chemistry of FACE A and C using the quantities of interest. However, in general, the information about flame chemistry and kinetics remains scarce; consequently, current reaction mechanisms are not capable of predicting actual fuel combustion properties, e.g., fuel reactivity and intermediate species profiles. Using current diagnostics, a detailed analysis of surrogate fuel combustion chemistry can be achieved to improve the current reaction mechanisms.

In this paper, the combustion chemistry of a binary mixture surrogate for gasoline fuels (primary reference fuel 84), is examined. PRF 84 ( $84 \%$ iso-octane and $16 \%$ n-heptane by volume), was chosen because it is a surrogate for research fuels FACE A and C [40, 41], which are under ongoing investigation by this research group. PRFs with different compositions have been studied by different research groups. Using a high pressure shock tube, Fikri et al. [42] studied the ignition delay time of two PRF mixtures (PRF 77.5 mixed with ethanol and PRF 55.5 mixed with toluene and diisobutylene). Both fuel mixtures had a research octane number (RON) of 95. Different mixtures pressures were investigated and the ignition delay results were correlated with respect to the pressure using the power law, where the first mixture had an exponent of -0.76 and 

times species time-histories for two FACE A and C gasolines and PRF 84. They showed that PRF 84 measurements agreed well with those of the FACE gasolines. Callahan et al. [44] performed numerical and experimental examination of the ignition delay time and the lowtemperature combustion of different PRF mixtures (n-heptane, PRF 62, 87, 90, 95, and isooctane). They used a variable-pressure reactor (VPR) and rapid compression machine (RCM) for their experiments. The results of the VPR highlighted the high reactivity of n-heptane over the other mixtures, having the highest heat release within the low temperature chemistry region (550K-900K). In addition, the negative-temperature coefficient (NTC) phenomenon was prominent for $n$-heptane, while this effect decreased with the increase of the iso-octane percentage in the PRF mixture. The ignition delay times also verified the same trends. Jerzembeck at al. [45] studied the laminar burning velocity of n-heptane, iso-octane, PRF 87, and gasoline fuels, with octane number of 90, at different pressures using a pressure vessel. The results showed that PRF87 had lower laminar burning velocity than n-heptane and higher than iso-octane. In addition, at high pressures above 20 bar, the differences between the laminar burning velocities start to diminish between different fuels. On the other hand, PRF 87 always had higher laminar burning velocities than gasoline. The laminar flame speed of PRF 0, 85, 90, 95, and 100 were determined using the twin flame of a counterflow burner by Huang et al. [46]. The results showed the same trends with the highest laminar flame speed for n-heptane, while small differences of the laminar flame speed of the rest of the mixtures were observed, especially under lean conditions. Similar laminar flame speeds were also observed for PRF 70, 85, and 95 in measurements by Mannaa et al. [37] in a constant-volume spherical vessel. On the other hand, the chemical kinetics modelling research community has provided different reaction mechanisms that represent the combustion of PRF mixtures under various conditions, e.g., automotive engine conditions [47] and low-temperature combustion in HCCI engines [48-50].

The goal of this research is to provide detailed analysis regarding the combustion chemistry of PRF 84 and to compare it with numerical simulations of the most recent reaction mechanisms. Major discrepancies between experimental and numerical findings are also detailed. Finally, major elementary reactions, responsible for the paramount disagreement between numerical and experimental results, are identified from a chemical kinetics viewpoint; and some suggestions are offered to improve the performance of the reaction mechanisms.

\section{Experimental Approach}

\subsection{Photoionization and Molecular Beam Mass Spectrometer}

Experiments presented in this paper were conducted at the 9.0.2 Chemical Dynamics Beamline at the Advanced Light Source (ALS), of Lawrence Berkeley National Laboratory. Photoionization occurred using synchrotron radiation available at the ALS. The 9.0.2 beamline received the photons from a $10 \mathrm{~cm}$ undulator with 43 periods. The synchrotron radiation passed 

undulator were removed. Afterwards, the photons passed through a 3-m Eagle monochromator for energy selection. The tunable, monochromatic light was then used for photoionization between (8-17 eV), for the gases sampled from the flame zone. More details about the 9.0.2 beamline at the ALS are available [51, 52]. The ions formed were then extracted into a $1.3-\mathrm{m}$ time-of-flight (TOF), mass spectrometer with mass resolution of $\mathrm{m} / \Delta \mathrm{m} \approx 3500$. The current of the photons through the ionization volume was measured using a photodiode with quantum efficiency, calibrated at the National Institute for Standards and Technology (NIST).

\subsection{Experimental Setup and Flame Conditions}

The experimental setup consisted of a stainless steel water-cooled McKenna burner $60 \mathrm{~mm}$ in diameter. A translational stage was used to allow for movement of $30 \mathrm{~mm}$ above the burner (HAB), during the gas sampling. The burner was placed in a pressure-controlled vacuum chamber set at 20 Torr for the experiments in this study. Calibrated MKS thermal flow controllers were used to regulate gas flow rates; the liquid fuel flow rate was controlled using a syringe pump. The regulated liquid fuel was then preheated to $130^{\circ} \mathrm{C}$ and mixed with argon, which is used as a diluent and a carrier gas for the vaporized liquid fuel. The oxidizer was oxygen with a $50 \%$ dilution of argon. Gas sampling was conducted using a $0.4 \mathrm{~mm}$ quartz cone forming a molecular beam and followed by a concentric skimmer collimator. The pressure behind the quartz cone (where the molecular beam is formed), was in the range of $10^{-4}$ Torr, while the pressure behind the skimmer collimator was in the range of $10^{-6}$ Torr, where ionization takes place (the ionization chamber).

Figure 1 presents a schematic diagram of the experimental setup, coupled with the time-of-flight mass spectrometer. Flame conditions were set at stoichiometric equivalence ratio with flow rates of $1.754 \mathrm{slm}$ oxygen, $1.898 \mathrm{slm}$ argon, and $1.035 \mathrm{ml} / \mathrm{min}$ of liquid fuel (84 vol\% iso-octane and 16 vol\% n-heptane, which is equivalent to $82.4 \mathrm{~mol} \%$ iso-octane and $17.6 \mathrm{~mol} \% \mathrm{n}$-heptane). The calculations of the equivalence ratio were conducted using a liquid fuel density of $690 \mathrm{~g} / \mathrm{lit}$, calculated at room temperature conditions; while the gaseous density of the fuel was calculated at standard conditions to be $4.98 \mathrm{~g} /$ lit. Several scans along the reaction zone were conducted between 8 and $17 \mathrm{eV}$, which are used for mole fraction calculations and distinguishing isobaric species. One energy scan was performed at a fixed axial location of $2.5 \mathrm{~mm}$, between 8 and 12 $\mathrm{eV}$, for the identification of photoionization onset of each species.

\subsection{Data Processing}

Mole fractions of the major species were calculated from the elemental mass balance of carbon, oxygen, and hydrogen at $\mathrm{HAB}$ of $30 \mathrm{~mm}$, where the fuel and intermediate species were depleted. Mole fractions of the other species are calculated from the signals collected from the TOF; the mole fractions and signals are linked via Eq. (1): 


$$
S_{i}=x_{i} \cdot c \cdot S W \cdot D_{i} \cdot \varphi \cdot F K T(h) \cdot \int \sigma_{i}(E) \cdot f(E) d E
$$

Where $S_{i}$ is the TOF raw signal, $x_{i}$ is the mole fraction of species $i, c$ is the machine constant, $S W$ is the number of sweeps, $D_{i}$ is the mass discrimination factor, $\varphi$ is the number of ionizing photons, $F K T(h)$ is the temperature-and-composition-dependent sampling function, $\sigma_{i}(E)$ is the photoionization cross-section of species $i$ at specific energy $E$, and $f(E)$ is the convolution function of energy distribution of the ionizing particle. In this study, the set photon energy was corrected using the resonant autoionization bands of $\mathrm{O}_{2}{ }^{+}$between $12 \mathrm{eV}$ and $13 \mathrm{eV}$ [53-55]. At the pertinent energy range (8-17 eV), the Gaussian distribution of the energy of the photons was minimal; typically the full width at half maximum (FWHM), of the energy is $<0.05 \mathrm{eV}[56,57]$. Thus the photoionization cross-section integration over the energy distribution range can be simplified as shown in Eq. (2):

$$
S_{i}=x_{i} \cdot c \cdot S W \cdot D_{i} \cdot \varphi \cdot F K T(h) \cdot \sigma_{i}(E)
$$

For the same burner scan, several parameters in Eq. (2), can be cancelled if a reference species is considered, thus Eq. 2 will be reduced to:

$$
\frac{S_{i}}{S_{R}}=\left(\frac{x_{i}}{x_{R}}\right) \cdot\left(\frac{D_{i}}{D_{R}}\right) \cdot\left(\frac{\sigma_{i}(E)}{\sigma_{R}(E)}\right)
$$

In order to calculate the mole fractions from Eq. (3), the photoionization cross-section (PICS), was obtained from the literature [58-65]. The mass discrimination factor was calculated using cold gas mixtures with calibrated composition over a wide range of molecular weights between hydrogen and xenon. The raw signal was subjected to several corrections in order to achieve the greatest possible accuracy. The first correction was for the contributions of fragments formed during the photoionization of higher molecules. The signal correction for fragmentation was applied to all the calculated species, using the cold flow scan of the fuel. In addition, fragmentation corrections were applied using calibrated cold gas mixtures. Furthermore, the signals were corrected for contributions from elemental isotopes of ${ }^{13} \mathrm{C}$ and ${ }^{18} \mathrm{O}$. The uncertainty of the mole fraction calculations for species with well-known PICS was in the range of 15-30\% [66]; and for other species, with higher uncertainty, the uncertainty can be up to a factor of 2. Additional details regarding data processing are available in Supplementary Material.

\subsection{Temperature Measurements}

The temperature profile along the flame zone was obtained using the proportionality between the sampling-cone-perturbed temperature and the pressure of the first stage behind the sampling cone [67], as described in Eq. (4): 
Where $p_{1 s t}$ is the pressure in the chamber behind the sampling cone, $\gamma$ is the specific heat ratio $\left(\mathrm{C}_{\mathrm{p}} / \mathrm{C}_{\mathrm{v}}\right), \bar{M}$ is the average molecular weight, $T$ is the local temperature, and $z=(\gamma+1) / 2(\gamma-2)$. The proportionality constant was obtained by measuring the temperature at $\mathrm{HAB}=30 \mathrm{~mm}$, using a Pt-Pt13\%Rh R-type thermocouple with alumina coating. The measured temperature was corrected for radiation losses, assuming an emissivity of 0.2 , Nusselt number of 2 , considering the thermocouple junction to be a sphere [68], and the thermocouple bead diameter is $0.51 \mathrm{~mm}$.

\section{Numerical simulations}

Numerical simulations were performed using PREMIX code of CHEMKIN PRO software. The probe-perturbed temperature measurements were used for the numerical simulations. The numerical simulations are affected by uncertainties in the temperature measurement. Therefore, our approach in this paper was to shift the experimental results 0.5 to $1 \mathrm{~mm}$ towards the burner to match the peaks of the numerical simulations and also to omit the data within the vicinity of the burner surface, which is typically subjected to significant probe perturbations [67, 69, 70]. A detailed chemical kinetics model was utilized for the simulation of $n$-heptane/iso-octane binary mixtures. The kinetic model is originally based on the model reaction mechanism by Lawrence Livermore National Laboratory (LLNL) [71]; however, with updated AramcoMech $2.0 \mathrm{C}_{0}-\mathrm{C}_{4}$ base chemistry [72-75] and updated $\mathrm{C}_{5}$ sub-mechanism [76]. The high temperature submechanisms of heptane and iso-octane was taken from [77] and [78], respectively. In their works, Zhang et al.[77] and Atef et al.[78] updated the rates of fuel abstraction by $\mathrm{OH}$ of both heptane and iso-octane using the rates from [79, 80], which account for next-nearest-neighbor (NNN) [81] effects, while also utilizing AramcoMech 2.0 base chemistry. The updated mechanisms for pure $n$-heptane [77] and pure iso-octane [78] were validated against a wide range of experimental data, in their respective published studies, particularly ignition delay time data and flame speeds at relatively high temperatures. The thermodynamic properties were updated using recent group values, and rate rules for sensitive reactions were revised based on measured or calculated rates. The updated mechanism was used for numerical predictions. Additionally, rate of production, sensitivity analysis, and chemical kinetics reaction rate analysis were performed to further explain the elementary reactions responsible for major differences between numerical predictions and experimental results.

\section{Results and Discussion}

The results are presented, starting with a flux analysis of n-heptane and iso-octane discussing the major high temperature pathways and intermediate species. The measured and simulated mole fractions of major species, followed by the prominent intermediate species; isomeric species are then presented and discussed, followed by radical species. 

respectively. The reaction pathways are at 20 Torr and $\mathrm{HAB}$ of $80 \%$ fuel consumption, which corresponds to $1097 \mathrm{~K}$ and $1245 \mathrm{~K}$ for $\mathrm{n}$-heptane and iso-octane, respectively. At high temperatures, $\mathrm{H}$ atom abstraction from the fuel is the major pathway followed by $\beta$-scission of the formed radicals. For $n$-heptane, high fluxes are shown for the formation of secondary radicals (34 and 31\%), as abstraction from secondary sites is easier than abstraction from primary sites. Due to the symmetry existing in the secondary $\mathrm{C}_{2}$ and $\mathrm{C}_{3}$ radicals, they are formed with higher fluxes (34 and 31\%) compared to the secondary $\mathrm{C}_{4}$ radical (14\%). The formed radicals undergo $\mathrm{C}-\mathrm{C}$ and $\mathrm{C}-\mathrm{H} \beta$-scission leading to alkenes and radicals. The alkenes undergo $\mathrm{H}$ abstraction forming an alkenyl radical or $\mathrm{H}$ addition forming a radical which further decomposes by $\beta$ scission. Iso-octane initially decomposes by $\mathrm{H}$ abstraction, in addition to a unimolecular decomposition reaction due to the slightly higher temperature compared to n-heptane. Although abstraction from primary is more difficult than abstraction form secondary and tertiary carbons, the highest fluxes (31\% and 22\%) are observed for the primary radicals due to the degeneracy, followed by secondary radical $(19 \%)$ and then tertiary radical $(15 \%)$. The formed radicals decompose by $\beta$-scission forming alkenes and radicals. The formed alkenes decompose via unimolecular decomposition, $\mathrm{H}$ abstraction or $\mathrm{H}$ addition. The formed radical from the $\mathrm{H}$ addition further decomposes via $\beta$-scission. Comparing the two species, $\mathrm{n}$-heptane forms linear radicals and alkenes, whereas iso-octane mainly produces branched intermediates. This leads to the relatively lower reactivity of iso-octane.

\subsection{Major Species}

Mole fraction profiles of the reactants (fuel, oxygen, and argon), and the major end-products $\left(\mathrm{CO}, \mathrm{CO}_{2}, \mathrm{H}_{2} \mathrm{O}\right.$, and $\left.\mathrm{H}_{2}\right)$, are presented in Fig. 4, along with the temperature profile. In general, good agreement was observed between experimental results and the numerical predictions, especially for the asymptotic values downstream of the burner. However, some discrepancy was noted in the $\mathrm{H}_{2}$ mole fraction between the experimental and numerical results, but it occurred within the combined uncertainty range of the experiments and modeling results. $\mathrm{H}_{2}$ mole fraction results typically show the highest uncertainty among all the major species because lower signal intensities that are due do to small mole fractions and experimental conditions (i.e., mass discrimination within the mass spectrometer). Utilization of the updated base chemistry did not show noticeable changes to the major species profiles. Results also revealed that total consumption of the fuel (>99\%), was attained at around $3 \mathrm{~mm} \mathrm{HAB}$, while the reaction continued downstream between the intermediate species and the radical species, which will be presented in the following section. It is also notable that the n-heptane gets consumed faster than the iso-octane, which is attributed to the higher reactivity of n-alkanes as compared to the branched-alkanes. 


\subsection{Intermediate Species}

Figure 5 presents the mole fraction profiles of $\mathrm{C}_{1}-\mathrm{C}_{3}$ alkanes. All three experimental profiles showed considerable value at $\mathrm{HAB}=0 \mathrm{~mm}$, compared to their maximum; this was attributed mainly to the fact that each experimental data point is $\sim 0.5-1 \mathrm{~mm}$ away from the burner in reality. Furthermore, the probe perturbations are substantial near the burner surface, and the back diffusion of intermediate species can contribute to the upstream signals obtained near the burner surface. The major discrepancy observed between the numerical and experimental data was related to the propane mole fraction, which was overestimated by a factor of $\sim 3.5$ at the peak. This may be due to the overestimation of the recombination reaction rates between $\mathrm{CH}_{3}$ and $\mathrm{C}_{2} \mathrm{H}_{5}$ or atomic $\mathrm{H}$ and $\mathrm{C}_{3} \mathrm{H}_{7}$, or underestimation of the hydrogen abstraction reaction from $\mathrm{C}_{3} \mathrm{H}_{8}$ via hydroxyl or atomic hydrogen radicals.

The mole fraction profiles of $\mathrm{C}_{2} \mathrm{H}_{2}, \mathrm{C}_{2} \mathrm{H}_{4}$, and $\mathrm{C}_{3} \mathrm{H}_{6}$ are presented in Fig. 6. In general, the $\mathrm{C}_{3} \mathrm{H}_{6}$ comparisons between the experimental and numerical predictions showed good agreement. The peak of the acetylene mole fraction was $\sim 0.5 \mathrm{~mm}$ downstream of the peak of both ethylene and propylene, which has also been reproduced numerically. The mechanism showed good prediction for the acetylene mole fraction, yet the ethylene mole fraction was underestimated by a factor of 2 .

To understand this disagreement, sensitivity analysis and rate of production were collectively examined to pinpoint the pivotal elementary reactions responsible for discrepancies. Positive sensitivity indicated reactions that promoted species production and increased its mole fraction, whereas negative sensitivity showed reactions that tended to decrease the mole fraction. The sensitivity and rate of production analyses were applied to ethylene as shown in Fig. 7. The sensitivity is implemented at $\mathrm{HAB}$ corresponding to the highest $\mathrm{C}_{2} \mathrm{H}_{4}$ mole fraction.

$\mathrm{C}_{2} \mathrm{H}_{4}$ kinetics analysis revealed that the reaction of $\mathrm{C}_{2} \mathrm{H}_{4}+\mathrm{OH} \leftrightarrow \mathrm{C}_{2} \mathrm{H}_{3}+\mathrm{H}_{2} \mathrm{O}$ showed negative sensitivity which leads to higher rates of ethylene consumption. Meanwhile, the production of $\mathrm{C}_{2} \mathrm{H}_{4}$ via the reaction of $\mathrm{C}_{3} \mathrm{H}_{6}+\mathrm{H} \leftrightarrow \mathrm{C}_{2} \mathrm{H}_{4}+\mathrm{CH}_{3}$, is highly sensitive. The rate of production analysis showed that these two reactions are also the main reactions of ethylene consumption and production, thus any change in these two reactions alters $\mathrm{C}_{2} \mathrm{H}_{4}$ mole fraction.

Fig. 8 describes the experimental results and numerical predictions of $\mathrm{C}_{1}-\mathrm{C}_{3}$ aldehydes. The experimental data revealed that formaldehyde presents $\sim 75 \%$ of the aldehydes in the reaction pool, which was captured by the numerical results. However, some discrepancies were observed for the propanal profile.

\subsection{Isomeric Species}

The use of synchrotron radiation enabled the differentiation among isomers of several species, provided that they do not have very close photoionization energy. On the other hand, species 

acetone $(\mathrm{IE}=9.7 \mathrm{eV})$ and 2-propen-1-ol $(\mathrm{IE}=9.67 \mathrm{eV})$. In this section, photoionization efficiency curves of the described isomeric species, as well as their mole fraction profiles, are examined.

Figure 9 shows the photoionization efficiency curve of the butene isomers ( $\mathrm{m} / \mathrm{z}=56$ signal), while the isomers contribution is presented by the weighted sum of the photoionization cross sections of each isomer. The ionization energies (IE) of 2-butene, iso-butene, and 1-butene are 9.11, 9.22, and $9.55 \mathrm{eV}$ respectively [64]. To segregate the first two isomers, the 2-butene mole fraction was calculated from a burner scan within the energy window of $9.1-9.22 \mathrm{eV}$, specifically at $9.15 \mathrm{eV}$. In principle, the signal-to-noise ratio is relatively weak at energies close to the IE; hence the mole fraction calculations of these two isomers contain additional uncertainty. All mole fractions were calculated from burner scans below $10 \mathrm{eV}$ (see Supplementary Material), because it has been reported in the literature that iso-octane produces many fragments in the form of $\mathrm{C}_{4} \mathrm{H}_{8}$ at energies above $10 \mathrm{eV}$ [82]. Mole fraction profiles of butene isomers are depicted in Fig. 10. The experimental trend was reproduced by the numerical simulations and the photoionization efficiency curves, where iso-butene is the dominant $\mathrm{C}_{4} \mathrm{H}_{8}$ isomer, followed by 1-butene and 2butene. However, the mechanism quantitatively underestimated the mole fractions of 1- and 2butene by a factor of 2 ; while iso-butene was overestimated by a factor of $\sim 3.5$. Since the fuel mixture contains primarily the highly branched iso-octane, the predominance of iso-butene is explicable. The consumption pathways of both fuel components at $80 \%$ of fuel consumed are presented in Fig. 3, where it can be seen that the pathways for $\mathrm{i}-\mathrm{C}_{4} \mathrm{H}_{8}$ are more significant compared to other butene isomers pathways.

Sensitivity and rate of production analysis are again used to understand the poor agreement of iso-butene numerical predictions with the experiment. From Fig. 11, one can see that several i$\mathrm{C}_{4} \mathrm{H}_{8}$ consumption reactions are equally sensitive. For example, $\mathrm{H}$-abstraction via $\mathrm{H}$ and $\mathrm{OH}$ are highly sensitive, also the $\mathrm{IC}_{4} \mathrm{H}_{8}+\mathrm{H} \leftrightarrow \mathrm{C}_{3} \mathrm{H}_{6}+\mathrm{CH}_{3}$ reaction. In addition, the most sensitive i$\mathrm{C}_{4} \mathrm{H}_{8}$ production reactions are directly related to iso-octane along with the reaction of iso-butane with peroxide radical.

Figure 12 describes the spectrum of $\mathrm{m} / \mathrm{z}=54$ where1,3-butadiene (IE=9.07 eV [65]) and 1-butyne ( $\mathrm{IE}=10.18 \mathrm{eV}$ [64]) can be distinguished from their IE onset. However, the weighted sum of photoionization efficiency curve did not reveal significant contributions from other isomers such as 1,2-butadiene and 2-butyne; this trend has been found in similar flame experiments [24, 83]. Figure 13 shows the mole fraction profiles of 1,3-butadiene and 1-butyne; their summation was compared with numerical predictions, since the reaction mechanism does not differentiate between $\mathrm{C}_{4} \mathrm{H}_{6}$ isomers. The formation of 1,3-butadiene is strongly dependent on the reaction between $\mathrm{C}_{4} \mathrm{H}_{7}$ and $\mathrm{H}$ radicals [84], as well as the recombination reaction between $\mathrm{C}_{3} \mathrm{H}_{3}$ and $\mathrm{CH}_{3}$, which can form 1,2 butadiene and 1-butyne [85, 86]. The absence of 1,2-butadiene in the reaction pool confirms the literature regarding its isomerization to 1,3-butadiene [85, 87]. Good agreement was observed numerically. 
Figure 14 presents the photoionization efficiency curve of $\mathrm{C}_{3} \mathrm{H}_{4}$ isomers. Superimposing the contribution of both isomers in the weighted sum at the $\mathrm{m} / \mathrm{z}=40$ agrees with the experimentally obtained photoionization efficiency curve of $\mathrm{m} / \mathrm{z}=40$. Figure 15 depicts the mole fraction profiles of allene and propyne. The reaction mechanism overestimated allene and propyne profiles. There is a consensus in the literature that propyne is more dominant over allene [24, 57, 83, 88, 89], which agrees with the experimental findings of this study, but not for the numerical predictions.

The high mole fraction of allene obtained from the numerical simulation is justified by the sensitivity and rate of production analysis shown in Fig. 16. The formation of allene relies on the presence of the intermediate species of $\mathrm{i}-\mathrm{C}_{4} \mathrm{H}_{7}$, which is formed via the $\mathrm{H}$-abstraction of $\mathrm{i}-\mathrm{C}_{4} \mathrm{H}_{8}$. On the other hand, allene consumption occurs directly via the reaction of $\mathrm{C}_{3} \mathrm{H}_{4}-\mathrm{a}+\mathrm{H} \leftrightarrow \mathrm{C}_{3} \mathrm{H}_{3}+$ $\mathrm{H}_{2}$ reactions, or the consumption of $\mathrm{i}-\mathrm{C}_{4} \mathrm{H}_{8}$ to form $\mathrm{C}_{3} \mathrm{H}_{6}$.

The propyne mole fraction was significantly overestimated. Figure 17 presents the sensitivity and rate of production analysis of propyne. The reaction of $\mathrm{C}_{3} \mathrm{H}_{4}-\mathrm{p}+\mathrm{H} \leftrightarrow \mathrm{CH}_{3}+\mathrm{C}_{2} \mathrm{H}_{2}$ was proven to be highly sensitive and it significantly consumed $\mathrm{C}_{3} \mathrm{H}_{4}-\mathrm{p}$. On the other hand, the $\mathrm{H}$ assisted isomerization reaction of allene $\left(\mathrm{C}_{3} \mathrm{H}_{4}-\mathrm{p}+\mathrm{H} \leftrightarrow \mathrm{C}_{3} \mathrm{H}_{4}-\mathrm{a}+\mathrm{H}\right)$ to form propyne showed high sensitivity and rate of production.

Figure 18 describes the photoionization efficiency curve of $\mathrm{m} / \mathrm{z}=70$ along with the IE of all $\mathrm{C}_{5}$ alkene isomers [64, 65, 90]. Comparison between the weighted sum of the photoionization efficiency curves and the numerical predictions, Fig. 19, revealed consistent agreement, wherein 1-pentene, 2-pentene, and 2-methyl-1-butene are the most dominant isomers, respectively. Consequently, the mole fraction calculation was conducted using an average value of the photoionization cross section of the three isomers. The experimentally calculated mole fraction depicts acceptable agreement with the total $\mathrm{C}_{5} \mathrm{H}_{10}$ numerical profile. A more powerful detection strategy, e.g., photoelectron photoion coincidence spectroscopy (PEPICO) [91], is needed for further investigation of such cases.

\subsection{Radical Species}

Mole fraction profiles of $\mathrm{CH}_{3}, \mathrm{C}_{2} \mathrm{H}_{5}, \mathrm{C}_{3} \mathrm{H}_{3}$, and $\mathrm{C}_{3} \mathrm{H}_{5}$ radicals are presented in Fig. 20 . Experimental results revealed that all the free radicals diminished close to HAB of $4 \mathrm{~mm}$. The numerical results showed longer existence, especially for the resonantly stable propargyl radical. In general, the reaction mechanism provided good agreement with most of the presented radical profiles. However, the mole fraction of $\mathrm{C}_{3} \mathrm{H}_{3}$ was greatly overestimated.

Sensitivity and rate of production analyses of propargyl in Fig. 21, show that the dissociation of both allene and propyne to form propargyl and hydrogen proved to have a significant role on the overestimated propargyl mole fraction. Propargyl production and consumption is also sensitive to other reactions which are responsible for the enhancement of the radical pool, but are not 
directly related to the species under interest, such as the reaction of $\mathrm{HCO}$ with $\mathrm{O}_{2}$ and $\mathrm{H}$ and the chain branching of $\mathrm{O}_{2}+\mathrm{H} \leftrightarrow \mathrm{O}+\mathrm{OH}$.

\section{Conclusions}

This work presented a detailed analysis of the combustion chemistry of a stoichiometric primary reference fuel 84 ( $84 \%$ iso-octane and $16 \%$ n-heptane) flame. The flame was stabilized at 20 Torr, and photoionization mass spectroscopy using the synchrotron radiation available at the Advanced Light Source of LBNL, was used for flame speciation. Stable, intermediate, free radical, and isomeric species, up to $\mathrm{C}_{5}$, were quantified and compared against numerical predictions. The major species profiles revealed the higher reactivity of $n$-heptane compared to iso-octane, where n-heptane is consumed faster in the reaction zone. A detailed kinetic model for n-heptane/iso-octane binary mixtures, with updated the latest sub-mechanisms for each fuel component and AramcoMech 2.0 base chemistry, was used for numerical simulations. Differences between the mechanistic pathways of n-heptane and iso-octane consumption were highlighted using the flux analysis of the adopted reaction mechanism. In general, numerical simulations showed good agreement with the experimental data; however, some discrepancies were observed; sensitivity and rate of production analyses were conducted to highlight the most sensitive reaction that is responsible for the discrepancies between experimental and numerical findings.

\section{Acknowledgments}

The authors acknowledge funding support from the Clean Combustion Research Center and from Saudi Aramco under the FUELCOM program. Measurements were performed by the flame team at the Advanced Light Source (ALS), Lawrence Berkeley National Laboratory. We thank everyone for assistance with data acquisition. Experiments at the Advanced Light Source (ALS), profited from the expert technical assistance of Paul Fugazzi. The ALS is supported by the Director, Office of Science, Office of Basic Energy Sciences, of the U.S. Department of Energy under Contract No. DEAC02-05CH11231. Sandia is a multi-program laboratory operated by Sandia Corporation, a Lockheed Martin Company, for the National Nuclear Security Administration under contract DE-AC04-94-AL85000.

\section{References}

1. T. Gallant; J. A. Franz; M. S. Alnajjar; J. M. E. Storey; S. A. Lewis; C. S. Sluder; W. J. Cannella; C. Fairbridge; D. Hager; H. Dettman; J. Luecke; M. A. Ratcliff; B. T. Zigler, Fuels for Advanced Combustion Engines Research Diesel Fuels: Analysis of Physical and Chemical Properties, SAE Int. J. Fuels Lubr. 22 (2009) 262-272. 

structure on auto-ignition behavior - Design rules for future high performance gasolines, Prog Energ Combust Sci 60 (2017) 1-25.

3. T. A. Cool; K. Nakajima; C. A. Taatjes; A. McIlroy; P. R. Westmoreland; M. E. Law; A. Morel, Studies of a fuel-rich propane flame with photoionization mass spectrometry, Proc Combust Inst 301 (2005) 1681-1688.

4. A. Lamprecht; B. Atakan; K. Kohse-Höinghaus, Fuel-rich flame chemistry in lowpressure cyclopentene flames, Proc Combust Inst 282 (2000) 1817-1824.

5. P. Oßwald; K. Kohse-Höinghaus; U. Struckmeier; T. Zeuch; L. Seidel; L. Leon; F. Mauss, Combustion chemistry of the butane isomers in premixed low-pressure flames, Z Phys Chem 225 9-10 (2011) 1029-1054.

6. B. W. Weber; K. Kumar; Y. Zhang; C.-J. Sung, Autoignition of n-butanol at elevated pressure and low-to-intermediate temperature, Combust Flame 1585 (2011) 809-819.

7. K. Moshammer; A. W. Jasper; D. M. Popolan-Vaida; A. Lucassen; P. Diévart; H. Selim; A. J. Eskola; C. A. Taatjes; S. R. Leone; S. M. Sarathy; Y. Ju; P. Dagaut; K. Kohse-Höinghaus; $\mathrm{N}$. Hansen, Detection and Identification of the Keto-Hydroperoxide (HOOCH2OCHO) and Other Intermediates during Low-Temperature Oxidation of Dimethyl Ether, J Phys Chem A 119 28 (2015) 7361-7374.

8. P. Dagaut; M. Cathonnet; J. c. Boettner, Kinetics of ethane oxidation, Int J Chem Kinet 235 (1991) 437-455.

9. $\quad$ S. M. Sarathy; M. J. Thomson; W. J. Pitz; T. Lu, An experimental and kinetic modeling study of methyl decanoate combustion, Proc Combust Inst 331 (2011) 399-405.

10. K. Moshammer; L. Seidel; Y. Wang; H. Selim; S. M. Sarathy; F. Mauss; N. Hansen, Aromatic ring formation in opposed-flow diffusive 1,3-butadiene flames, Proc Combust Inst).

11. A. Alfazazi; U. Niemann; H. Selim; R. J. Cattolica; S. M. Sarathy, Effects of Substitution on Counterflow Ignition and Extinction of C3 and C4 Alcohols, Energ Fuel 307 (2016) 60916097.

12. C. S. McEnally; L. D. Pfefferle, Soot formation in methane/air nonpremixed flames doped with small quantities of C3 hydrocarbons, Combust Flame 1124 (1998) 545-558.

13. C. S. McEnally; L. D. Pfefferle, Species and Soot Concentration Measurements in a Methane/Air Nonpremixed Flame Doped With C4 Hydrocarbons, Combust Flame 115 1-2 (1998) 81-92.

14. H. Selim; A. Al Shoaibi; A. K. Gupta, Effect of H2S in methane/air flames on sulfur chemistry and products speciation, Appl Energ 888 (2011) 2593-2600.

15. H. Selim; A. Al Shoaibi; A. K. Gupta, Fate of sulfur with H2S injection in methane/air flames, Appl Energ 920 (2012) 57-64.

16. H. Selim; S. Ibrahim; A. Al Shoaibi; A. K. Gupta, Investigation of sulfur chemistry with acid gas addition in hydrogen/air flames, Appl Energ 1130 (2014) 1134-1140.

17. Y. Wang; H. Selim; K. Moshammer; N. Hansen; S. M. Sarathy; S. H. Chung in: A photoionization mass spectrometry study of ethylene counterflow diffusion flames doped with methane and propane, ASPACC 2015 - 10th Asia-Pacific Conference on Combustion, 2015; 2015.

18. H. Selim; S. Ibrahim; A. Al Shoaibi; A. K. Gupta, Effect of oxygen enrichment on acid gas combustion in hydrogen/air flames under claus conditions, Appl Energ 109 (2013) 119-124. 19. H. Selim; A. Al Shoaibi; A. K. Gupta, Experimental examination of flame chemistry in hydrogen sulfide-based flames, Appl Energ 888 (2011) 2601-2611. 

stream on H2S combustion, Appl Energ 98 (2012) 53-58.

21. H. Selim; A. K. Gupta; A. Al Shoaibi, Effect of reaction parameters on the quality of captured sulfur in Claus process, Appl Energ 104 (2013) 772-776.

22. S. Mani Sarathy; U. Niemann; C. Yeung; R. Gehmlich; C. K. Westbrook; M. Plomer; Z. Luo; M. Mehl; W. J. Pitz; K. Seshadri; M. J. Thomson; T. Lu, A counterflow diffusion flame study of branched octane isomers, Proc Combust Inst 341 (2013) 1015-1023.

23. S. M. Sarathy; C. Yeung; C. K. Westbrook; W. J. Pitz; M. Mehl; M. J. Thomson, An experimental and kinetic modeling study of n-octane and 2-methylheptane in an opposed-flow diffusion flame, Combust Flame 1587 (2011) 1277-1287.

24. H. Selim; S. Y. Mohamed; A. Lucassen; N. Hansen; S. M. Sarathy, Effect of the Methyl Substitution on the Combustion of Two Methylheptane Isomers: Flame Chemistry Using Vacuum-Ultraviolet (VUV) Photoionization Mass Spectrometry, Energ Fuel 294 (2015) 26962708.

25. W. Wang; Z. Li; M. A. Oehlschlaeger; D. Healy; H. J. Curran; S. M. Sarathy; M. Mehl; W. J. Pitz; C. K. Westbrook, An experimental and modeling study of the autoignition of 3methylheptane, Proc Combust Inst 341 (2013) 335-343.

26. K. Anand; Y. Ra; R. Reitz; B. Bunting, Surrogate model development for fuels for advanced combustion engines, Energ Fuel 254 (2011) 1474-1484.

27. I. P. Androulakis; M. D. Weisel; C. S. Hsu; K. Qian; L. A. Green; J. T. Farrell; K. Nakakita, An integrated approach for creating model diesel fuels, Energ Fuel 191 (2005) 111119.

28. C. J. Mueller; W. J. Cannella; T. J. Bruno; B. Bunting; H. D. Dettman; J. A. Franz; M. L. Huber; M. Natarajan; W. J. Pitz; M. A. Ratcliff, Methodology for formulating diesel surrogate fuels with accurate compositional, ignition-quality, and volatility characteristics, Energ Fuel 266 (2012) 3284-3303.

29. E. Singh; J. Badra; M. Mehl; S. M. Sarathy, Chemical Kinetic Insights into the Octane Number and Octane Sensitivity of Gasoline Surrogate Mixtures, Energ Fuel (2017).

30. G. T. Kalghatgi, The outlook for fuels for internal combustion engines, Int J Engine Res (2014) 1468087414526189.

31. J. A. Cooke; M. Bellucci; M. D. Smooke; A. Gomez; A. Violi; T. Faravelli; E. Ranzi, Computational and experimental study of JP-8, a surrogate, and its components in counterflow diffusion flames, Proc Combust Inst 301 (2005) 439-446.

32. W. Liu; R. Sivaramakrishnan; M. J. Davis; S. Som; D. Longman; T. Lu, Development of a reduced biodiesel surrogate model for compression ignition engine modeling, Proc Combust Inst 341 (2013) 401-409.

33. T. Gallant; J. A. Franz; M. S. Alnajjar; J. M. Storey; S. A. Lewis; C. S. Sluder; W. J. Cannella; C. Fairbridge; D. Hager; H. Dettman, in: SAE Technical Paper: 2009.

34. S. S. Vasu; D. F. Davidson; R. K. Hanson, Jet fuel ignition delay times: Shock tube experiments over wide conditions and surrogate model predictions, Combust Flame 1521 (2008) 125-143.

35. O. A. Kuti; M. Sarathy; K. Nishida; W. Roberts, in: SAE Technical Paper: 2014.

36. A. Elwardany; S. Sazhin; A. Farooq, Modelling of heating and evaporation of gasoline fuel droplets: a comparative analysis of approximations, Fuel 111 (2013) 643-647. 

elevated pressures for gasoline and gasoline surrogates associated with RON, Combust Flame 1626 (2015) 2311-2321.

38. G. Shibata; K. Oyama; T. Urushihara; T. Nakano, in: SAE Technical Paper: 2005.

39. H. Selim; S. Y. Mohamed; A. E. Dawood; S. M. Sarathy, Understanding premixed flame chemistry of gasoline fuels by comparing quantities of interest, Proc Combust Inst (2016).

40. M. Sjöberg; J. E. Dec, Comparing late-cycle autoignition stability for single-and twostage ignition fuels in HCCI engines, Proc Combust Inst 312 (2007) 2895-2902.

41. D. Vuilleumier; H. Selim; R. Dibble; M. Sarathy, in: SAE Technical Paper: 2013.

42. M. Fikri; J. Herzler; R. Starke; C. Schulz; P. Roth; G. Kalghatgi, Autoignition of gasoline surrogates mixtures at intermediate temperatures and high pressures, Combust Flame 1521 (2008) 276-281.

43. T. Javed; E. F. Nasir; E.-t. Es-sebbar; A. Farooq, A comparative study of the oxidation characteristics of two gasoline fuels and an n-heptane/iso-octane surrogate mixture, Fuel 140 (2015) 201-208.

44. C. V. Callahan; T. J. Held; F. L. Dryer; R. Minetti; M. Ribaucour; L. R. Sochet; T. Faravelli; P. Gaffuri; E. Rani, Experimental data and kinetic modeling of primary reference fuel mixtures, Symp. Int. Combust. Proc. 261 (1996) 739-746.

45. S. Jerzembeck; N. Peters; P. Pepiot-Desjardins; H. Pitsch, Laminar burning velocities at high pressure for primary reference fuels and gasoline: Experimental and numerical investigation, Combust Flame 1562 (2009) 292-301.

46. Y. Huang; C. Sung; J. Eng, Laminar flame speeds of primary reference fuels and reformer gas mixtures, Combust Flame 1393 (2004) 239-251.

47. H. J. Curran; W. J. Pitz; C. K. Westbrook; G. V. Callahan; F. L. Dryer, Oxidation of automotive primary reference fuels at elevated pressures, Symp. Int. Combust. Proc. 271 (1998) 379-387.

48. M. Mehl; W. Pitz; M. Sjöberg; J. E. Dec, in: SAE Technical Paper: 2009.

49. T. Tsurushima, A new skeletal PRF kinetic model for HCCI combustion, Proc Combust Inst 322 (2009) 2835-2841.

50. M. Waqas; N. Naser; M. Sarathy; K. Morganti; K. Al-Qurashi; B. Johansson, Blending Octane Number of Ethanol in HCCI, SI and CI Combustion Modes, SAE Int. J. Fuels Lubr. 93 (2016) 659-682.

51. A. G. Suits; P. Heimann; X. Yang; M. Evans; C. W. Hsu; K. t. Lu; Y. T. Lee; A. Kung, A differentially pumped harmonic filter on the Chemical Dynamics Beamline at the Advanced Light Source, Rev. Sci. Instrum. 6610 (1995) 4841-4844.

52. P. A. Heimann; M. Koike; C.-W. Hsu; D. Blank; X. Yang; A. G. Suits; Y. Lee; M. Evans; C. Ng; C. Flaim, Performance of the vacuum ultraviolet high-resolution and high-flux beamline for chemical dynamics studies at the Advanced Light Source, Rev. Sci. Instrum. 685 (1997) 1945-1951.

53. J. Eland, Vibrational level populations in the autoionization of oxygen, J Chem Phys 72 11 (1980) 6015-6019.

54. R. Huffman; J. Larrabee; Y. Tanaka, Absorption Coefficients of Oxygen in the 1060580-Å Wavelength Region, J Chem Phys 402 (1964) 356-365.

55. K. i. Tanaka; I. Tanaka, Photoelectron spectra from some autoionizing states of $\mathrm{O} 2$ near the ionization threshold, J Chem Phys 599 (1973) 5042-5049. 

Ahmed, Photoionization mass spectrometer for studies of flame chemistry with a synchrotron light source, Rev. Sci. Instrum. 769 (2005) 094102.

57. T. Kasper; P. Oßwald; U. Struckmeier; K. Kohse-Höinghaus; C. A. Taatjes; J. Wang; T. Cool; M. Law; A. Morel; P. R. Westmoreland, Combustion chemistry of the propanol isomersinvestigated by electron ionization and VUV-photoionization molecular-beam mass spectrometry, Combust Flame 1566 (2009) 1181-1201.

58. C. Backx; G. Wight; M. Van der Wiel, Oscillator strengths (10-70 eV) for absorption, ionization and dissociation in H2, HD and D2, obtained by an electron-ion coincidence method, J Phys B: At Mol Phys 92 (1976) 315.

59. J. C. Robinson; N. E. Sveum; D. M. Neumark, Determination of absolute photoionization cross sections for isomers of C $3 \mathrm{H} \mathrm{5:}$ allyl and 2-propenyl radicals, Chem Phys Lett 3835 (2004) 601-605.

60. J. D. Savee; S. Soorkia; O. Welz; T. M. Selby; C. A. Taatjes; D. L. Osborn, Absolute photoionization cross-section of the propargyl radicala), J Chem Phys 13613 (2012) 134307.

61. R. I. Schoen, Absorption, Ionization, and Ion-Fragmentation Cross Sections of Hydrocarbon Vapors under Vacuum-Ultraviolet Radiation, J Chem Phys 379 (1962) 2032-2041. 62. V. A. Shubert; S. T. Pratt, Photodissociation of Acetaldehyde and the Absolute Photoionization Cross Section of HCO†, J Phys Chem A 11442 (2010) 11238-11243.

63. B. Steiner; C. F. Giese; M. G. Inghram, Photoionization of alkanes. Dissociation of excited molecular ions, J Chem Phys 341 (1961) 189-220.

64. J. Wang; B. Yang; T. A. Cool; N. Hansen; T. Kasper, Near-threshold absolute photoionization cross-sections of some reaction intermediates in combustion, Int $\mathrm{J}$ Mass Spectrom 2693 (2008) 210-220.

65. B. Yang; J. Wang; T. A. Cool; N. Hansen; S. Skeen; D. L. Osborn, Absolute photoionization cross-sections of some combustion intermediates, Int J Mass Spectrom 309 (2012) 118-128.

66. F. N. Egolfopoulos; N. Hansen; Y. Ju; K. Kohse-Höinghaus; C. K. Law; F. Qi, Advances and challenges in laminar flame experiments and implications for combustion chemistry, Prog Energ Combust Sci 43 (2014) 36-67.

67. A. Lucassen; N. Labbe; P. R. Westmoreland; K. Kohse-Höinghaus, Combustion chemistry and fuel-nitrogen conversion in a laminar premixed flame of morpholine as a model biofuel, Combust Flame 1589 (2011) 1647-1666.

68. C. R. Shaddix, in: Sandia National Labs., Livermore, CA (US): 1999.

69. N. Hansen; T. A. Cool; P. R. Westmoreland; K. Kohse-Höinghaus, Recent contributions of flame-sampling molecular-beam mass spectrometry to a fundamental understanding of combustion chemistry, Prog Energ Combust Sci 352 (2009) 168-191.

70. U. Struckmeier; P. Oßwald; T. Kasper; L. Böhling; M. Heusing; M. Köhler; A. Brockhinke; K. Kohse-Höinghaus, Sampling probe influences on temperature and species concentrations in molecular beam mass spectroscopic investigations of flat premixed lowpressure flames, Z Phys Chem 223 4-5 (2009) 503-537.

71. M. Mehl; W. Pitz; M. Sarathy; Y. Yang; J. E. Dec, in: SAE International: 2012.

72. Y. Li; C.-W. Zhou; K. P. Somers; K. Zhang; H. J. Curran, The oxidation of 2-butene: A high pressure ignition delay, kinetic modeling study and reactivity comparison with isobutene and 1-butene, Proc Combust Inst (2016). 
73. C.-W. Zhou; Y. Li; E. O'Connor; K. P. Somers; S. Thion; C. Keesee; O. Mathieu; E. L. Petersen; T. A. DeVerter; M. A. Oehlschlaeger; G. Kukkadapu; C.-J. Sung; M. Alrefae; F. Khaled; A. Farooq; P. Dirrenberger; P.-A. Glaude; F. Battin-Leclerc; J. Santner; Y. Ju; T. Held; F. M. Haas; F. L. Dryer; H. J. Curran, A comprehensive experimental and modeling study of isobutene oxidation, Combust Flame 167 (2016) 353-379.

74. S. M. Burke; U. Burke; R. Mc Donagh; O. Mathieu; I. Osorio; C. Keesee; A. Morones; E. L. Petersen; W. Wang; T. A. DeVerter; M. A. Oehlschlaeger; B. Rhodes; R. K. Hanson; D. F. Davidson; B. W. Weber; C.-J. Sung; J. Santner; Y. Ju; F. M. Haas; F. L. Dryer; E. N. Volkov; E. J. K. Nilsson; A. A. Konnov; M. Alrefae; F. Khaled; A. Farooq; P. Dirrenberger; P.-A. Glaude; F. Battin-Leclerc; H. J. Curran, An experimental and modeling study of propene oxidation. Part 2: Ignition delay time and flame speed measurements, Combust Flame 1622 (2015) 296-314.

75. S. M. Burke; W. Metcalfe; O. Herbinet; F. Battin-Leclerc; F. M. Haas; J. Santner; F. L. Dryer; H. J. Curran, An experimental and modeling study of propene oxidation. Part 1: Speciation measurements in jet-stirred and flow reactors, Combust Flame 16111 (2014) 27652784.

76. J. Bugler; K. P. Somers; E. J. Silke; H. J. Curran, Revisiting the Kinetics and Thermodynamics of the Low-Temperature Oxidation Pathways of Alkanes: A Case Study of the Three Pentane Isomers, J Phys Chem A 11928 (2015) 7510-7527.

77. K. Zhang; C. Banyon; J. Bugler; H. J. Curran; A. Rodriguez; O. Herbinet; F. BattinLeclerc; C. B'Chir; K. A. Heufer, An updated experimental and kinetic modeling study of nheptane oxidation, Combust Flame 172 (2016) 116-135.

78. N. Atef; G. Kukkadapu; S. Y. Mohamed; M. Al Rashidi; C. Banyon; M. Mehl; A. Heufer; E. F. Nasir; A. Alfazazi; A. K. Das; C. K. Westbrook; W. J. Pitz; T. Lu; A. Farooq; C.-J. Sung; H. J. Curran; S. M. Sarathy, A Comprehensive Iso-octane Combustion Model with Improved Thermochemistry and Chemical kinetics, Combust Flame (2016) Submitted.

79. R. Sivaramakrishnan; J. V. Michael, Rate Constants for $\mathrm{OH}$ with Selected Large Alkanes: Shock-Tube Measurements and an Improved Group Scheme, J Phys Chem A 11317 (2009) 5047-5060.

80. J. Badra; A. Farooq, Site-specific reaction rate constant measurements for various secondary and tertiary H-abstraction by OH radicals, Combust Flame 1625 (2015) 2034-2044.

81. N. Cohen, Are reaction rate coefficients additive? Revised transition state theory calculations for $\mathrm{OH}+$ alkane reactions, Int J Chem Kinet 235 (1991) 397-417.

82. Z. Zhou; L. Zhang; M. Xie; Z. Wang; D. Chen; F. Qi, Determination of absolute photoionization cross-sections of alkanes and cyclo-alkanes, Rapid Commun Mass Sp 249 (2010) 1335-1342.

83. N. Hansen; T. Kasper; S. J. Klippenstein; P. R. Westmoreland; M. E. Law; C. A. Taatjes; K. Kohse-Höinghaus; J. Wang; T. A. Cool, Initial steps of aromatic ring formation in a laminar premixed fuel-rich cyclopentene flame, J Phys Chem A 11119 (2007) 4081-4092.

84. V. Dias; J. Vandooren, Experimental and modeling study of a lean premixed isobutene/hydrogen/oxygen/argon flame, Fuel 899 (2010) 2633-2639.

85. H. Wang; M. Frenklach, A detailed kinetic modeling study of aromatics formation in laminar premixed acetylene and ethylene flames, Combust Flame 110 1-2 (1997) 173-221.

86. Y. Hidaka; T. Higashihara; T. Oki; H. Kawano, Thermal decomposition of 1-butyne in shock waves, Int J Chem Kinet 274 (1995) 321-330. 
87. Y. Hidaka; T. Higashihara; N. Ninomiya; T. Oki; H. Kawano, Thermal isomerization and decomposition of 1,2-butadiene in shock waves, Int J Chem Kinet 274 (1995) 331-341.

88. M. Schenk; L. Leon; K. Moshammer; P. Oßwald; T. Zeuch; L. Seidel; F. Mauss; K. Kohse-Höinghaus, Detailed mass spectrometric and modeling study of isomeric butene flames, Combust Flame 1603 (2013) 487-503.

89. N. Hansen; J. A. Miller; P. R. Westmoreland; T. Kasper; K. Kohse-Höinghaus; J. Wang; T. A. Cool, Isomer-specific combustion chemistry in allene and propyne flames, Combust Flame 15611 (2009) 2153-2164.

90. T. A. Cool; J. Wang; K. Nakajima; C. A. Taatjes; A. Mcllroy, Photoionization cross sections for reaction intermediates in hydrocarbon combustion, Int J Mass Spectrom 2471 (2005) 18-27.

91. D. Felsmann; K. Moshammer; J. Krüger; A. Lackner; A. Brockhinke; T. Kasper; T. Bierkandt; E. Akyildiz; N. Hansen; A. Lucassen, Electron ionization, photoionization and photoelectron/photoion coincidence spectroscopy in mass-spectrometric investigations of a lowpressure ethylene/oxygen flame, Proc Combust Inst 351 (2015) 779-786. 


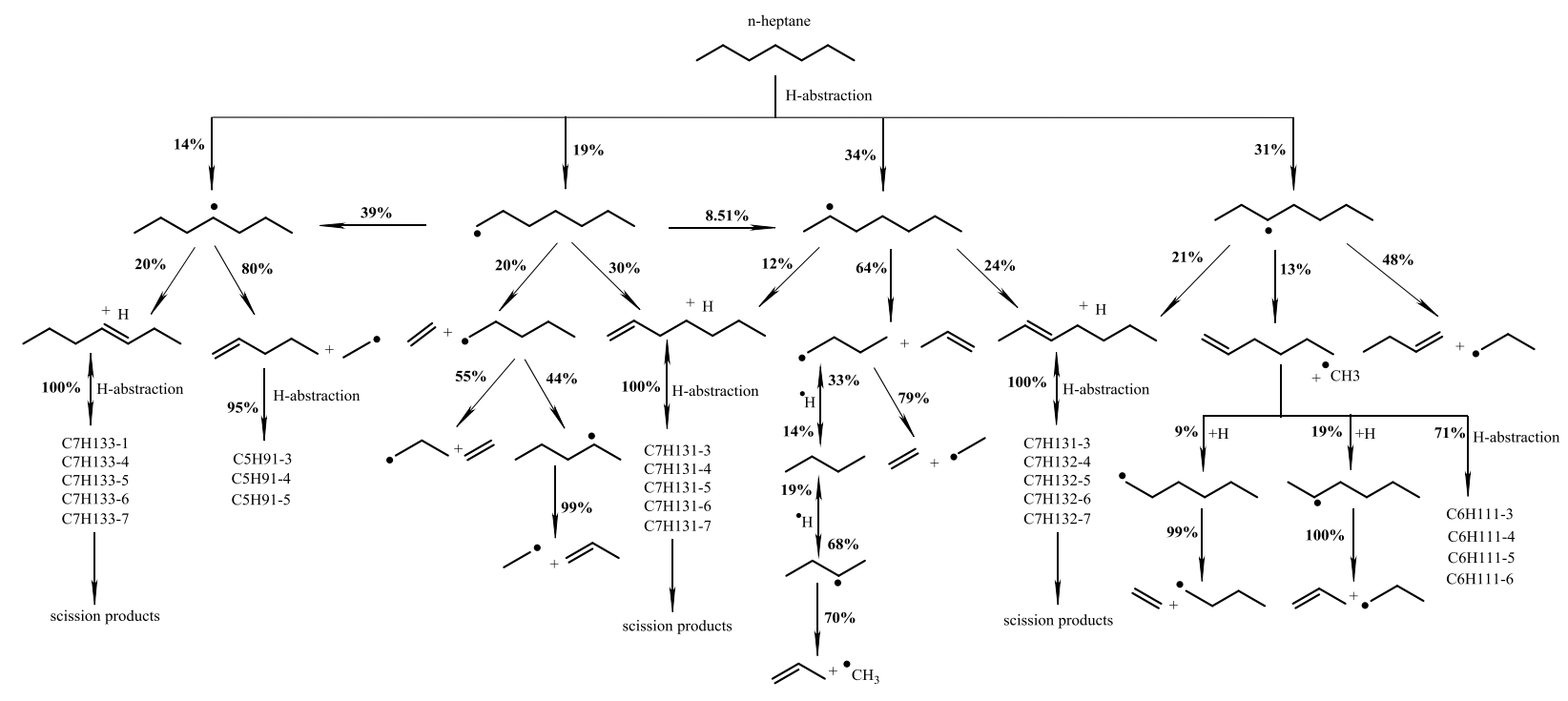

Figure 2. Flux analysis at 20 Torr, $1097 \mathrm{~K}$ at $80 \%$ consumption of n-heptane. 
Figure 3. Flux analysis at 20 Torr, $1245 \mathrm{~K}$ at $80 \%$ consumption of iso-octane.
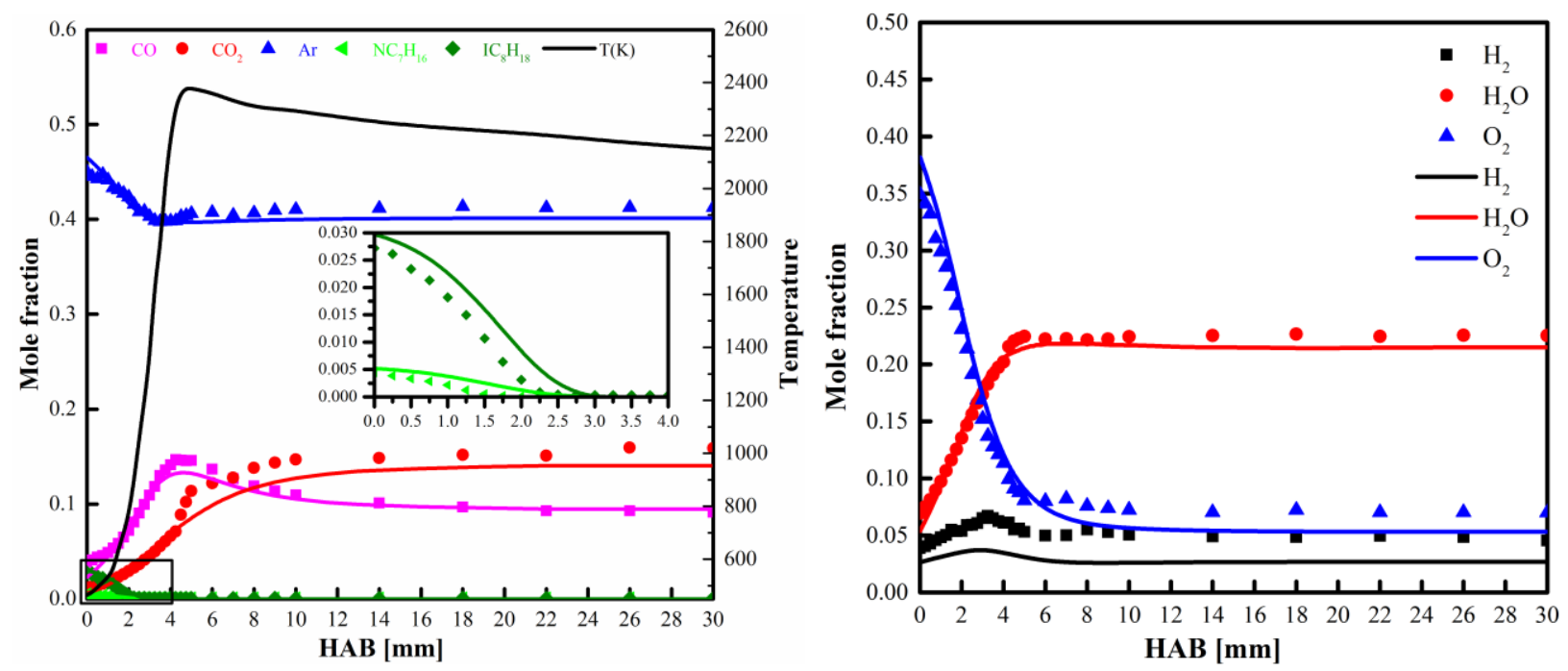

Figure 4. Major species mole fraction profiles. Experimental (symbols), numerical (lines). 


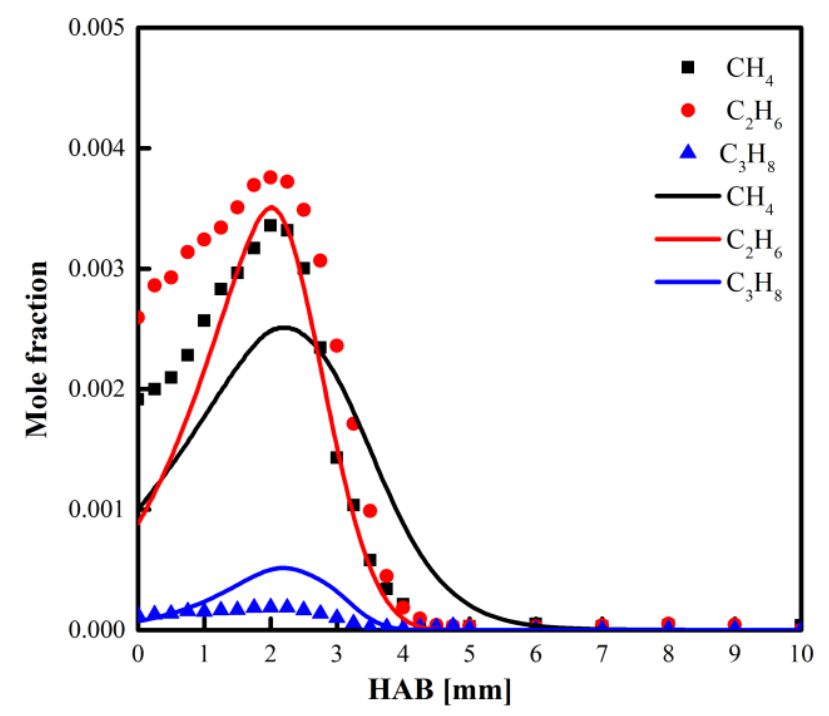

Figure 5. $\mathrm{C}_{1}-\mathrm{C}_{3}$ alkanes mole fraction profiles. Experimental (symbols), numerical (lines).

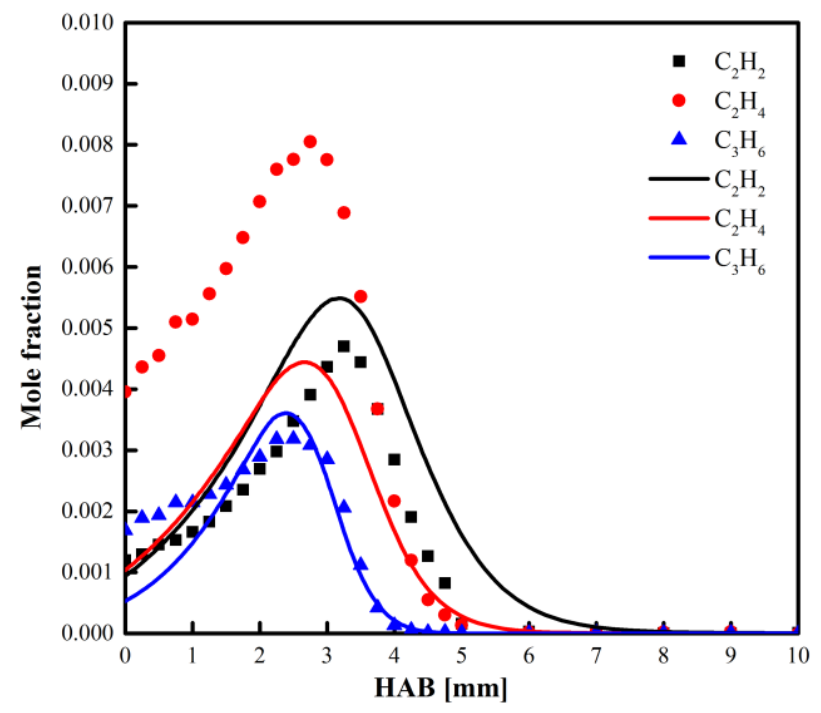

Figure 6. $\mathrm{C}_{2} \mathrm{H}_{2}, \mathrm{C}_{2} \mathrm{H}_{4}$, and $\mathrm{C}_{3} \mathrm{H}_{6}$ mole fraction profiles. Experimental (symbols), numerical (lines). 


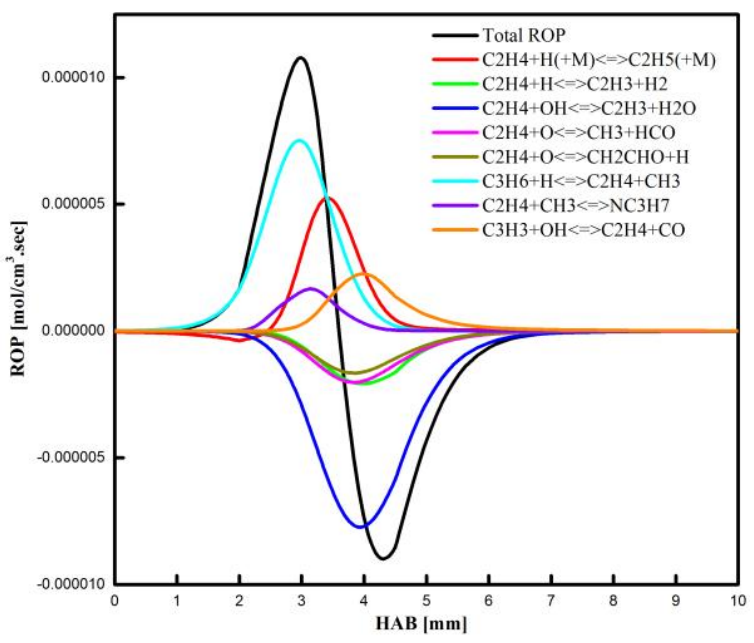

Figure 7. $\mathrm{C}_{2} \mathrm{H}_{4}$ sensitivity analysis and rate of production.

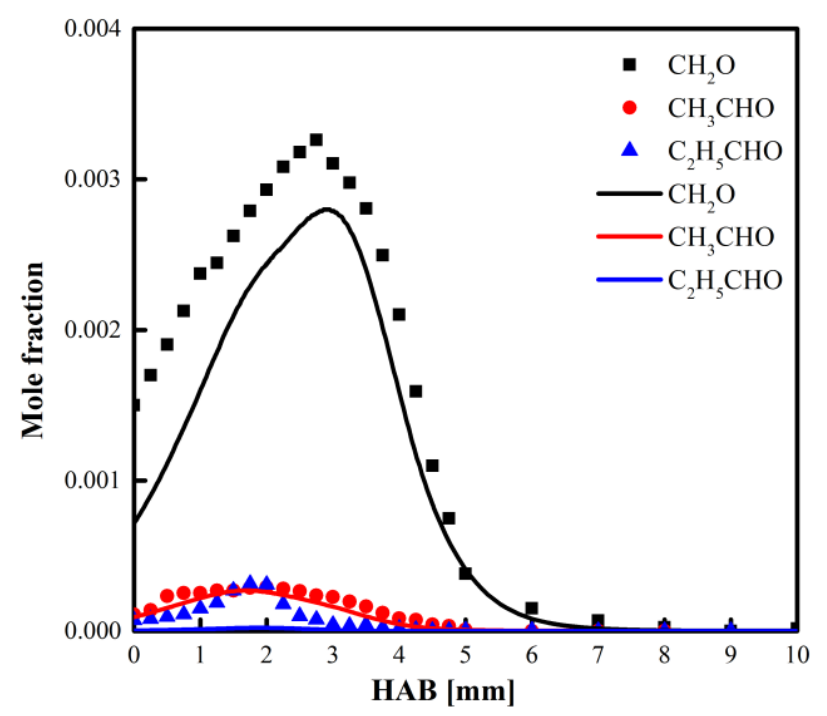

Figure 8. $\mathrm{C}_{1}-\mathrm{C}_{3}$ aldehydes mole fraction profiles. Experimental (symbols), numerical (lines). 


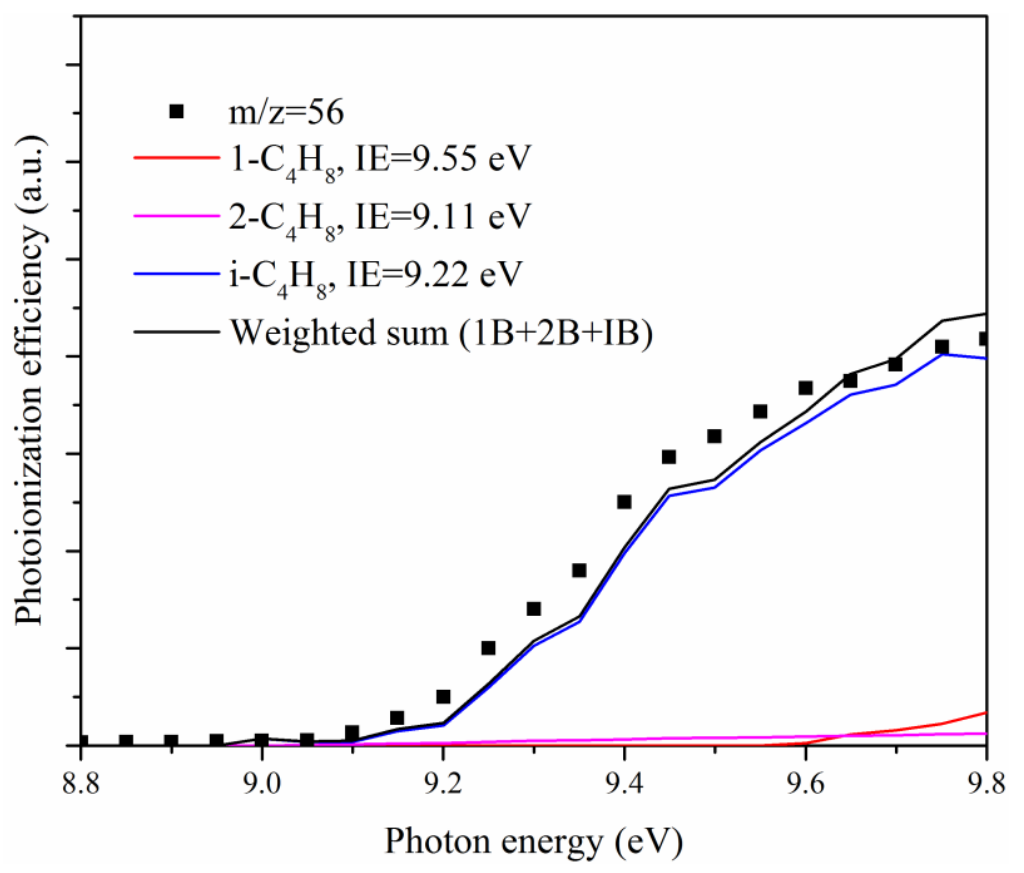

Figure 9. Photoionization efficiency curve of butene isomers, 1-butene (IB), 2-butene (2B), and iso-butene (IB).

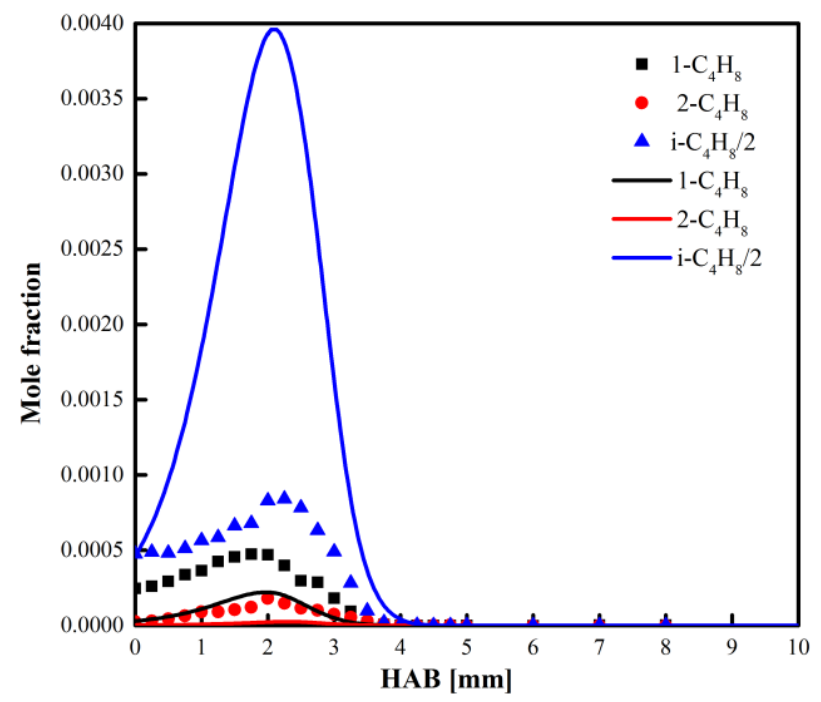

Figure 10. Butene isomers mole fraction profiles. Experimental (symbols), numerical (lines). 


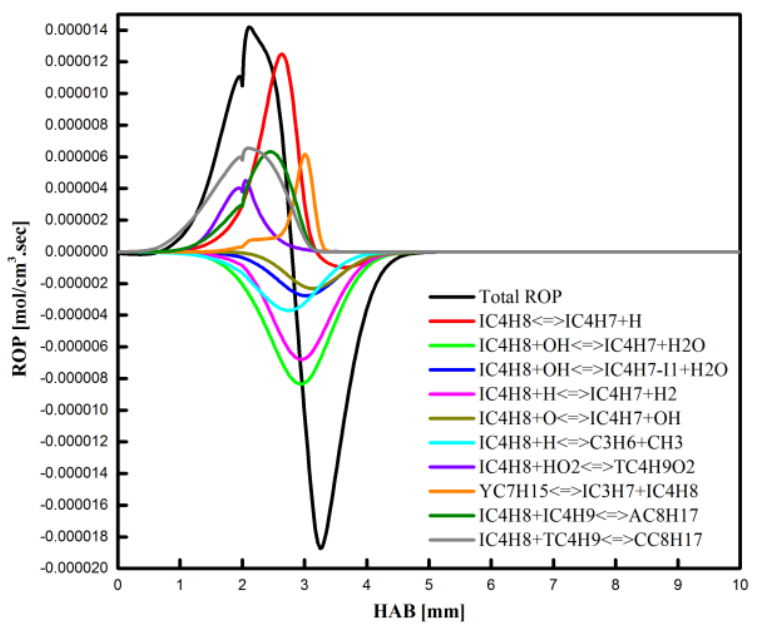

Figure 11. $\mathrm{i}-\mathrm{C}_{4} \mathrm{H}_{8}$ sensitivity analysis and rate of production.

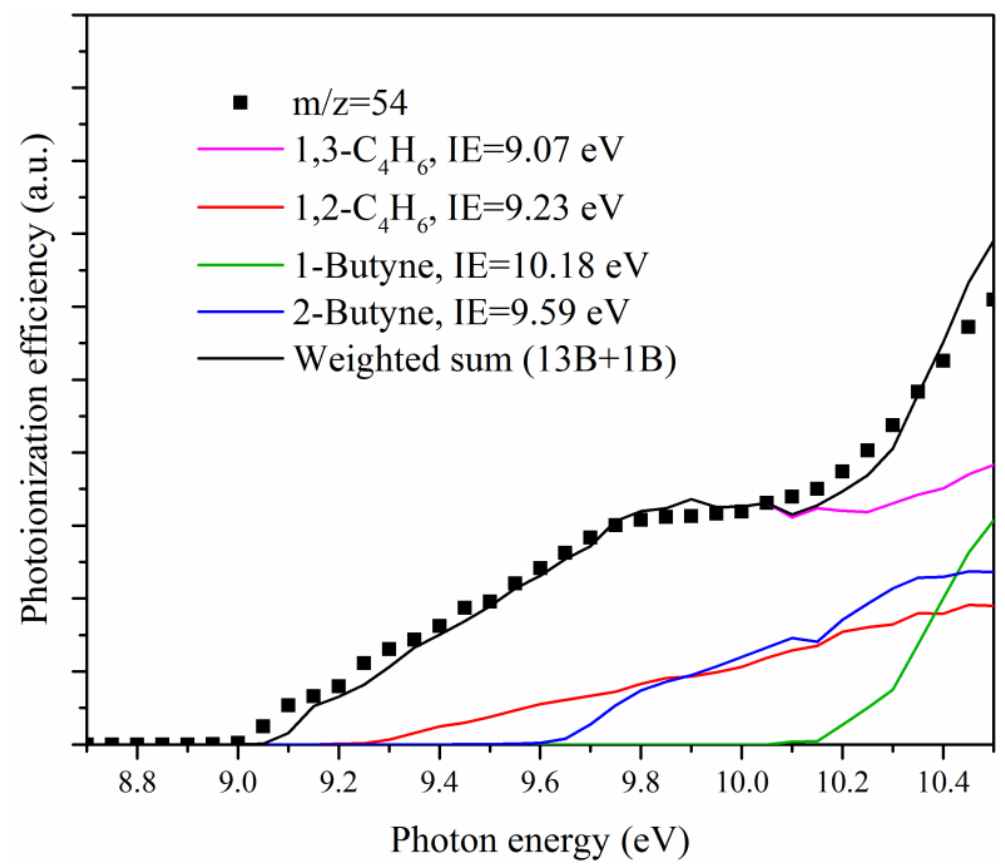

Figure 12. Photoionization efficiency curve of $\mathrm{C}_{4} \mathrm{H}_{6}$ isomers, 1,2-butadiene (12B), 1,3-butadiene (13B), 1-butyne (1B), and 2-butyne (2B). 


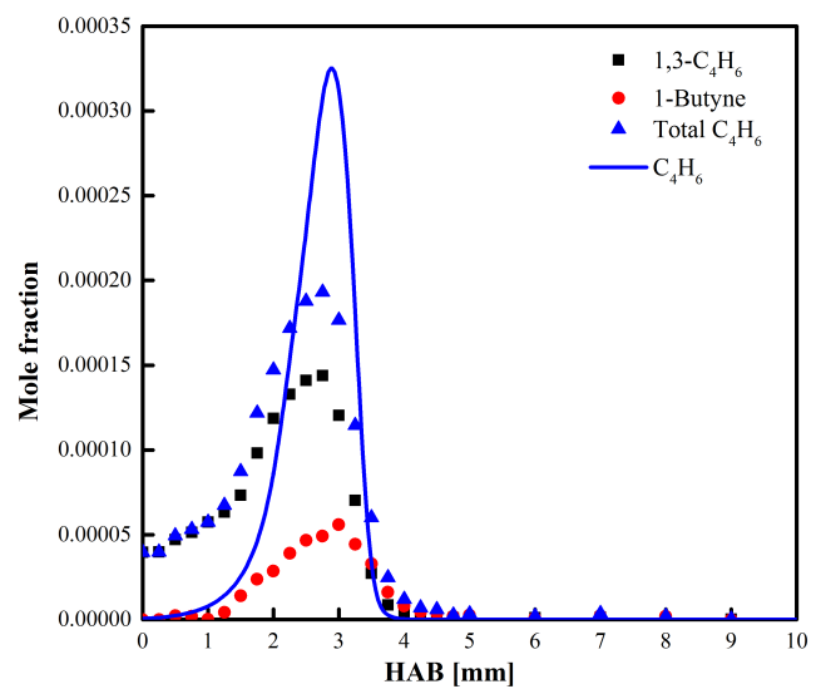

Figure 13. $\mathrm{C}_{4} \mathrm{H}_{6}$ isomer mole fraction profiles. Experimental (symbols), numerical (lines).

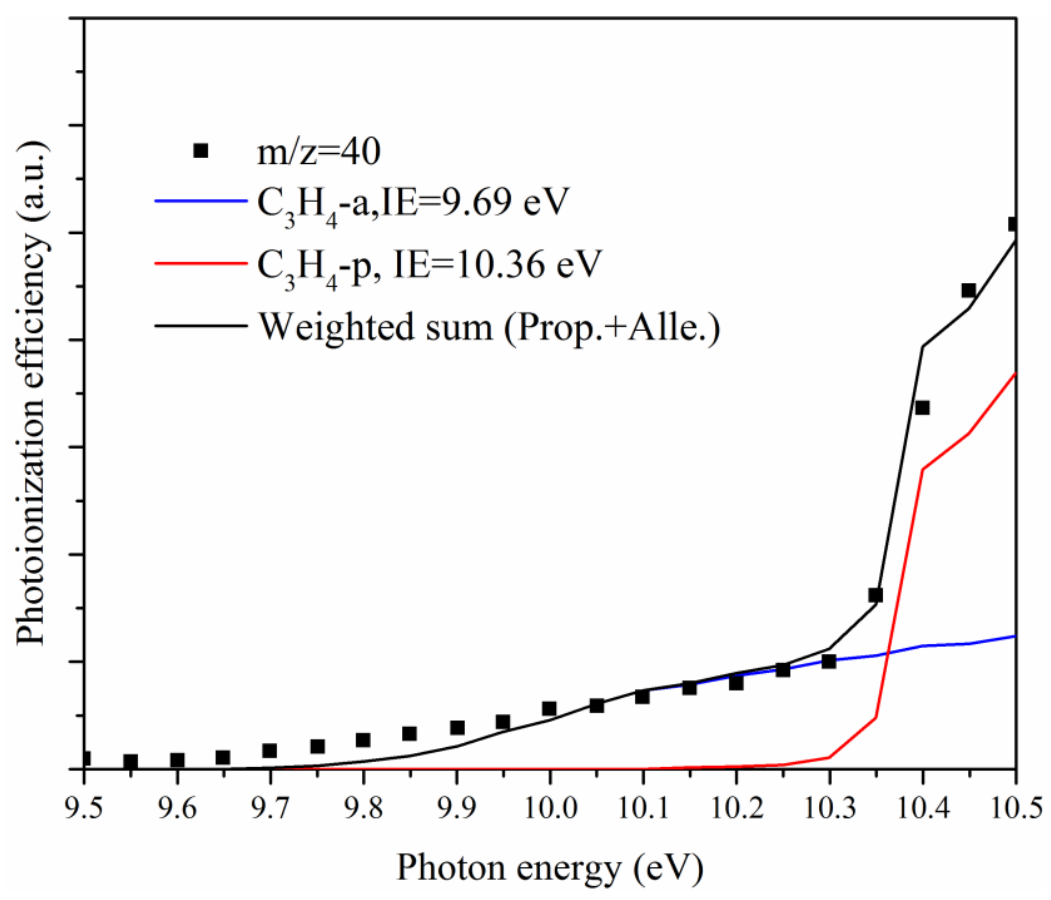

Figure 14. Photoionization efficiency curve of $\mathrm{C}_{3} \mathrm{H}_{4}$ isomers, allene (Alle.) and propyne (Prop.). 


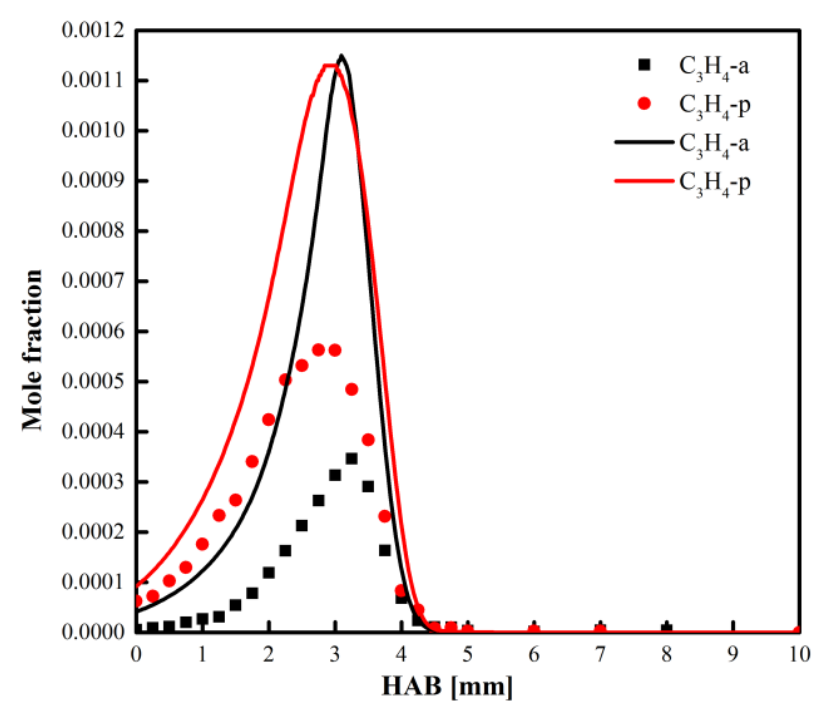

Figure 15. $\mathrm{C}_{3} \mathrm{H}_{4}$ isomers mole fraction profiles. Experimental (symbols), numerical (lines).
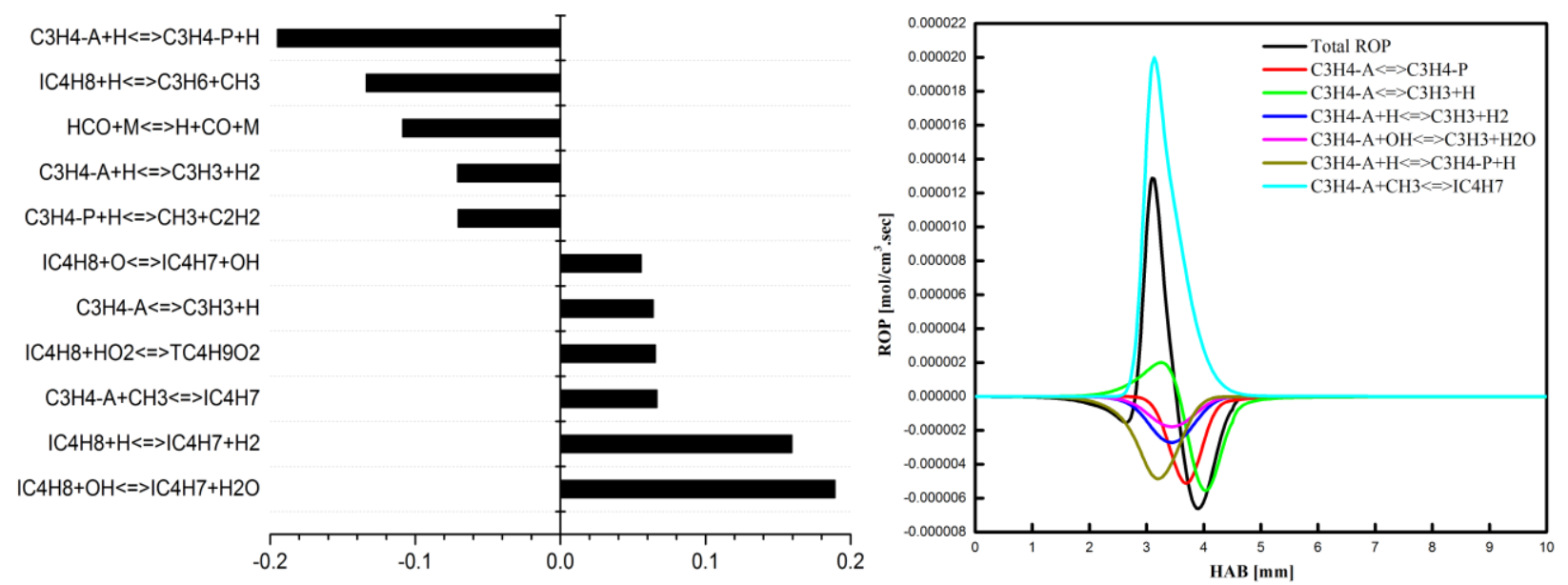

Figure $16 . \mathrm{C}_{3} \mathrm{H}_{4}$-a sensitivity analysis and rate of production. 

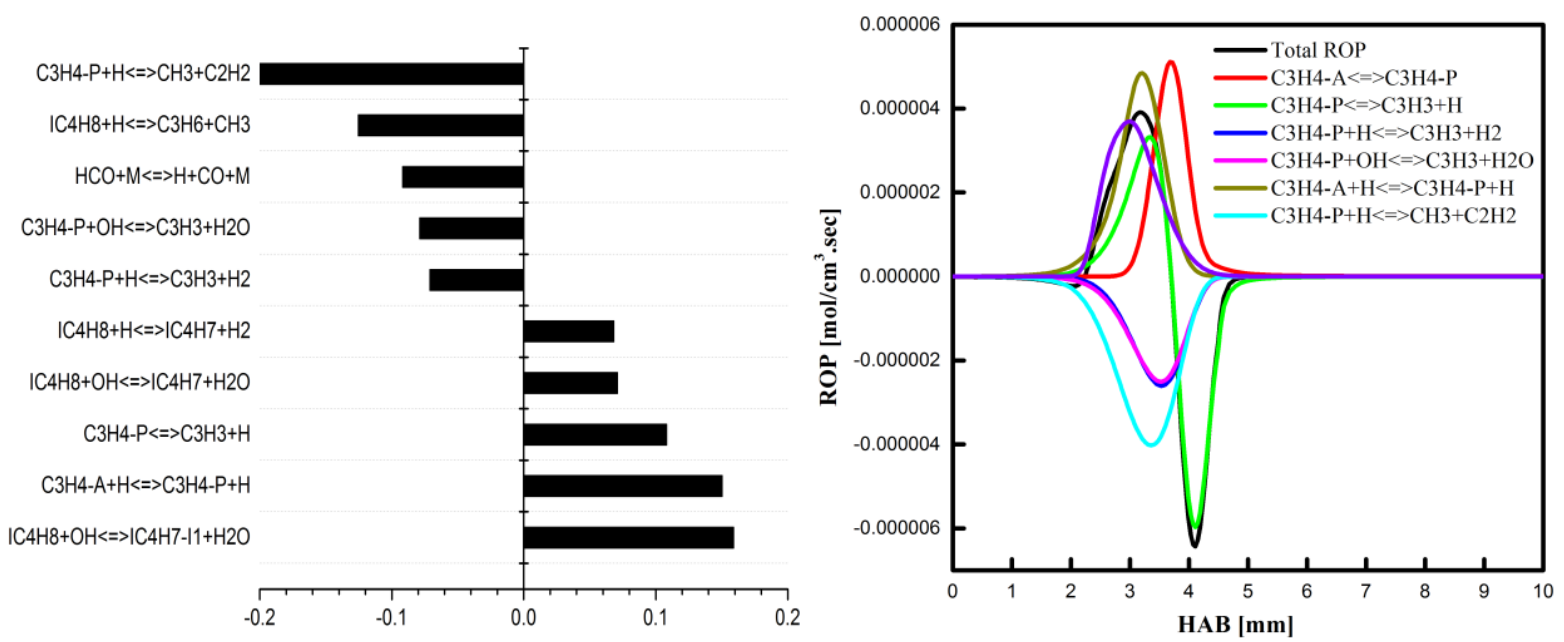

Figure 17. $\mathrm{C}_{3} \mathrm{H}_{4}-\mathrm{p}$ sensitivity analysis and rate of production.

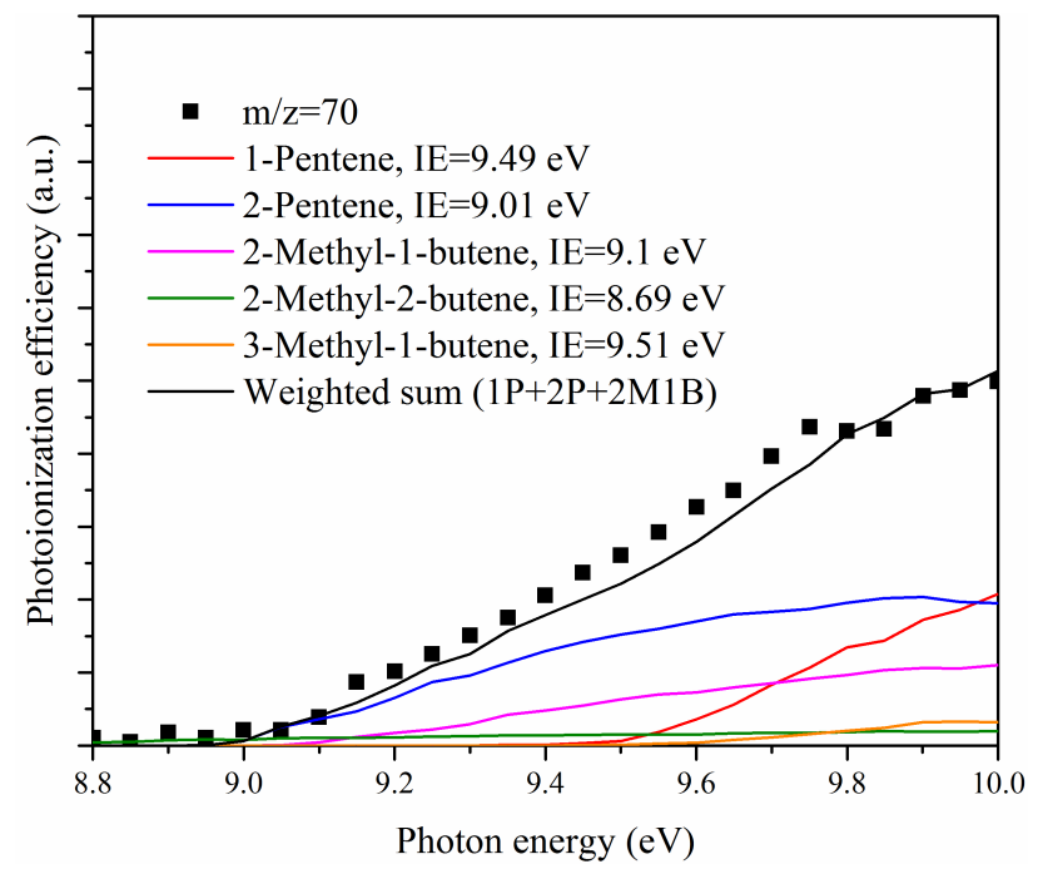

Figure 18. Photoionization efficiency curve of $\mathrm{C}_{5} \mathrm{H}_{10}$ isomers, 1-pentene (1P), 2-pentene (2P), 2 methyl-1-butene (2M1B), 2-methyl-2-butene (2M2B), and 3-methyl-1-butene (3M1B). 


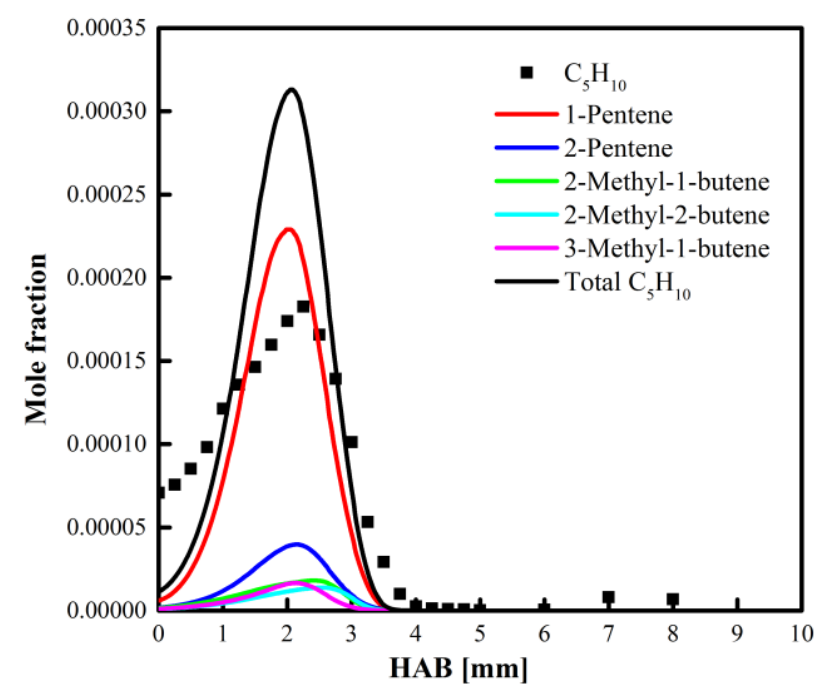

Figure 19. Mole fraction profiles of $\mathrm{C}_{5} \mathrm{H}_{10}$. Experimental (symbols), numerical (lines).

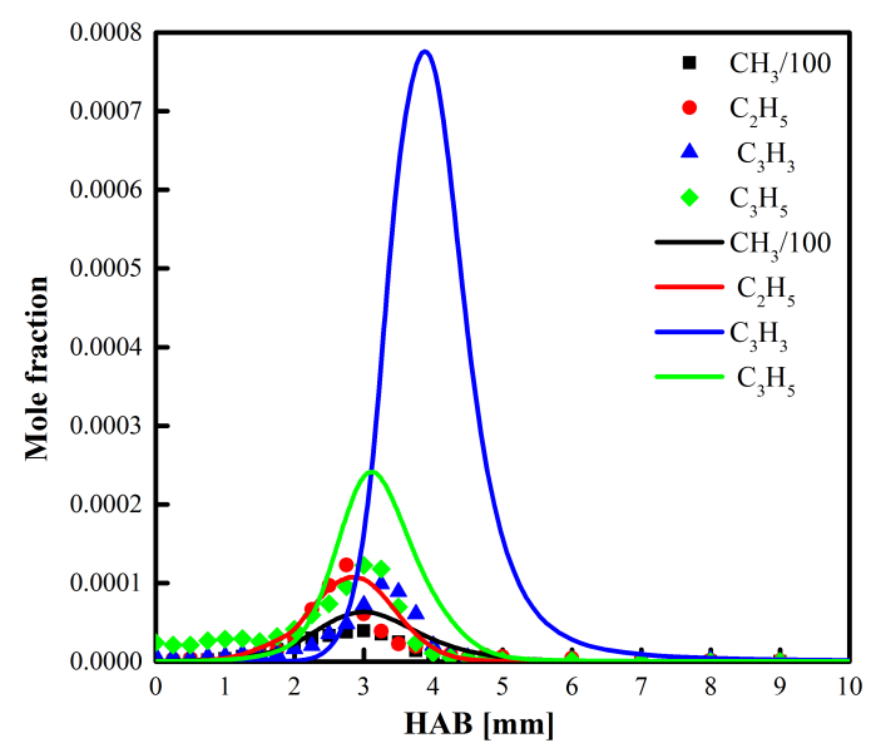

Figure 20. Radical mole fraction profiles. Experimental (symbols), numerical (lines). 


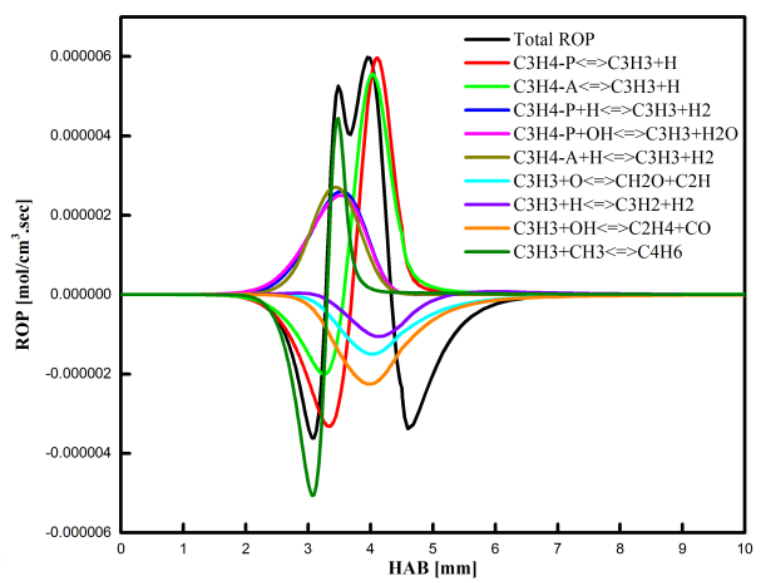

Figure $21 . \mathrm{C}_{3} \mathrm{H}_{3}$ sensitivity analysis and rate of production. 